\title{
Novel Nitro Derivatives of Benzothiadiazine 1,1-Dioxide as Aldose Reductase Inhibitors
}

\author{
Shaoqi YANG, Xiangyu QIN, Tianwei LUO, Xin HAO, Changjin ZHU* \\ Department of Applied Chemistry, School of Chemical Engineering and Environment, Beijing Institute of \\ Technology, Zhongguancun South Street, 100081 Beijing, China
}

ABSTRACT: Novel nitro-benzothiadiazine 1,1-dioxide derivatives were synthesized and tested for their inhibitory activity against aldose reductase. Of them, 5-nitro and 8-nitro bearing ones displayed significant activity in $\mathrm{IC}_{50}$ values of 4.6 and $13.45 \mu \mathrm{M}$. Their docking behaviors were also studied.

KEYWORD: Nitro compound; benzothiadiazine 1,1-dioxide; aldose reductase inhibitor

\section{INSTRUCTION}

Diabetes mellitus as a chronic life-threatening disease that is spreading around the world make most patients suffer from so-called long-term complications, such as neuropathy, nephropathy, retinopathy and cataracts [1-2]. The development and progression of the complications are related to the activation and/or overexpression of the enzyme aldose reductase (ALR2, EC 1.1.1.21), which is a member of the aldo-keto reductase superfamily [3]. Under hyperglycemic conditions, the polyol pathway (Figure 1) becomes activated, and it leads to the accumulation of sorbitol and then to diabetic complications [4]. ALR2 as the rate-limiting enzyme catalyses the NADPH-dependent reduction of glucose to sorbitol in the first step of this metabolic pathway [5]. Therefore, it is possible by inhibition of the enzyme as drug target to prevent or delay the onset and progression of diabetic complications, independently of glycaemic levels.

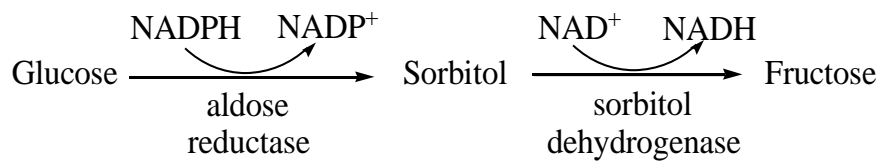

Figure 1. The polyol pathway of glucose metabolism.

In the past decades, a range of structurally different compounds (Figure 2) as ALR2 inhibitors (ARIs) have been reported. However, epalrestat of the carboxylic acid (Figure 2) is still the only ARI in clinical use as a drug in Japan and more recently in
China and India [6-7] because of the adverse pharmacokinetics, toxic side effects or low efficacy. Most of the typical carboxylic acid ARIs showed potent in vitro activity but their effectiveness decreases in vivo. In their turn, the cyclic imide ARIs often develop toxicity and exhibit some side effects [8].

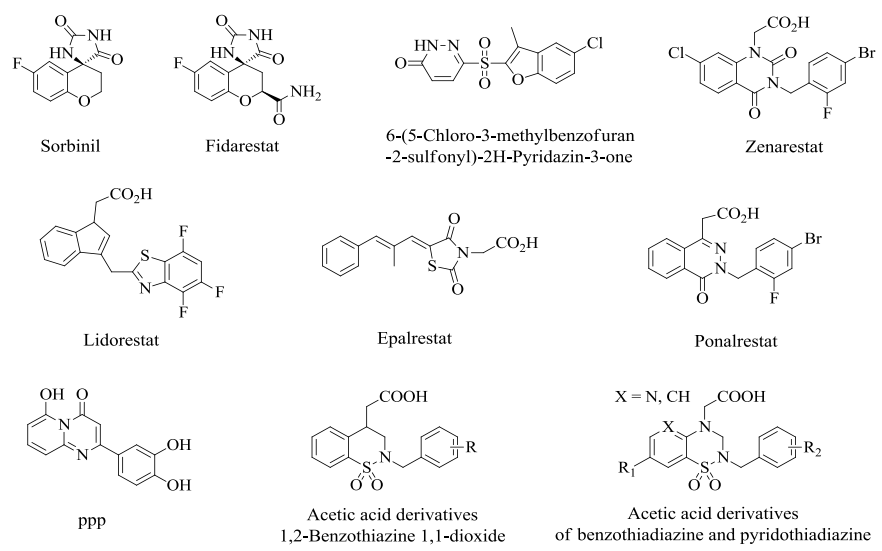

Figure 2. Chemical structures of aldose reductase inhibitors.

Thus, more effort into the development of a larger variety of ARIs that inhibit ALR2 strongly and specifically is still needed. We have recently designed a number of potent ARIs based on the scaffolds of benzothiadiazine 1,1-dioxide and quinoxalinone. The present study is focusing on benzothiadiazine-based nitro derivatives during the course of searching for non-carboxylic acid ARIs. Here, we report their preparation, aldose reductase inhibition activity, and docking studies. 


\section{RESULTS AND DISCUSSION}

\subsection{Chemistry}

Nitro-benzothiadiazine 1,1-dioxide derivatives $(\mathbf{9 a - b}$ and 11a-b) and 2-(7-bromo-1,1-dioxido- $4 \mathrm{H}$ benzo[e][1,2,4]thiadiazin-4-yl)acetic acid were prepared following the synthetic pathway depicted in Scheme 1 [7a]. 7-Bromo-4H-benzo[e] [1,2,4] thiadiazine 1,1-dioxide 4 prepared in our previous work [7a], was nitrified at the $\mathrm{N} 4$ position with sulfuric acid and concentrated nitric acid (volume=1:1) to form nitro-benzothiadiazine 1,1dioxide derivatives 7a-c. Reduction of the double bond at the 2,3 positions of $\mathbf{7 a - b}$ with sodium borohydride gave compounds $\mathbf{8}$ and $\mathbf{1 0}$. A benzyl group was introduced at the $\mathrm{N} 2$ position with benzyl bromide to provide compounds $\mathbf{9 a - b}$ and 11a-b.

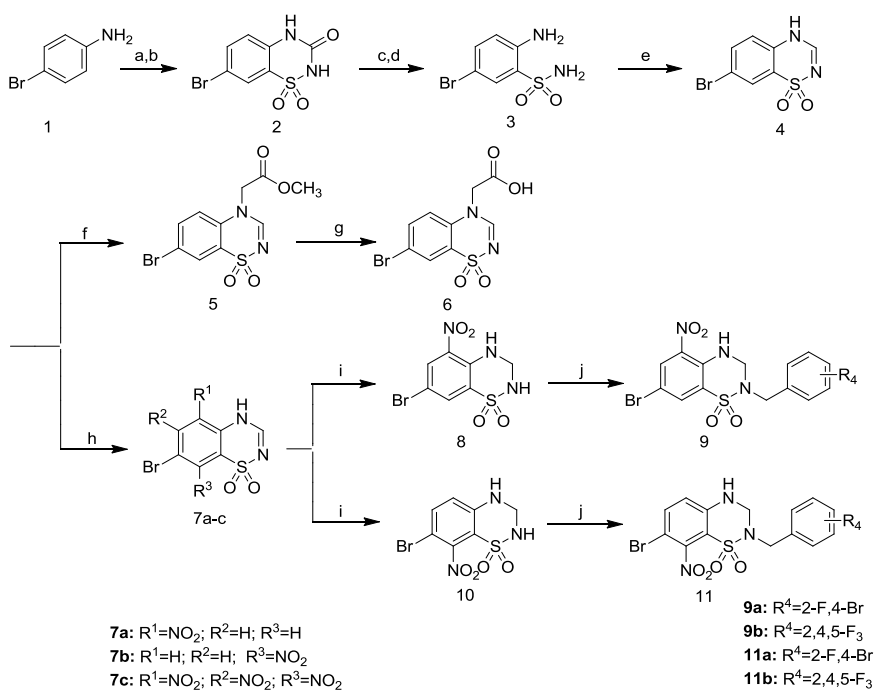

Scheme 1. Reagents and conditions: a) $\mathrm{ClSO}_{2} \mathrm{NCO}, \mathrm{CH}_{3} \mathrm{NO}_{2}$, $40{ }^{\circ} \mathrm{C}, 0.5 \mathrm{~h}$; b) $\mathrm{AlCl}_{3}, 110{ }^{\circ} \mathrm{C}, 1 \mathrm{~h}, 66 \%$; c) $50 \% \mathrm{H}_{2} \mathrm{SO}_{4}$, $140{ }^{\circ} \mathrm{C}, 6 \mathrm{~h}$; d) $\mathrm{NaOH}(\mathrm{aq}), 0{ }^{\circ} \mathrm{C}, 0.5 \mathrm{~h}, 45 \%$; e) $\mathrm{HC}(\mathrm{OEt})_{3}$, reflux, $2 \mathrm{~h}, 88 \%$; f) $\mathrm{BrCH}_{2} \mathrm{COOCH}_{3}, \mathrm{~K}_{2} \mathrm{CO}_{3}, \mathrm{CH}_{3} \mathrm{CN}, 75{ }^{\circ} \mathrm{C}$, 2 h, $82 \%$; g) 1,4-dioxane, NaOH, RT, 2 h, $83 \%$; h) $98 \%$ $\mathrm{H}_{2} \mathrm{SO}_{4}: 65 \% \mathrm{HNO}_{2}=1: 1, \mathrm{RT}, 0.5 \mathrm{~h}, 30-36 \%$; i) $\mathrm{NaBH}_{4}, 1,4-$ dioxane , $0{ }^{\circ} \mathrm{C}, 15 \mathrm{~min}, 70-75 \%$; j) $\mathrm{Bn}-\mathrm{Br}, \mathrm{K}_{2} \mathrm{CO}_{3}, \mathrm{CH}_{3} \mathrm{CN}$, $70{ }^{\circ} \mathrm{C}, 2 \mathrm{~h}, 69-86 \%$.

All reactions were routinely checked by TLC on silica gel Merck 60F254. NMR spectra were recorded on a Bruker Advance 400 spectrometer (Bruker (Beijing) Technologies \& Services Co., Ltd), while ${ }^{13} \mathrm{C}$ NMR spectra were recorded at 100 $\mathrm{MHz}$ in DMSO-d 6 .

\subsection{ALR2 inhibition}

All newly synthesized nitro derivatives of 1,2benzothiazine 1,1-dioxide were tested for their potential inhibitory effect on ALR2 isolated from rat lenses. Most of the compounds showed good activity in the ALR2 inhibition as shown in Table 1. Among them, 7a was the most active compound with an $\mathrm{IC}_{50}$ value of $4.6 \mu \mathrm{M}$. In contrast, the nitro derivative 11a was the least effective with an inhibition ratio of $9.34 \%$ at a concentration of $10 \mu \mathrm{M}$. It is noteworthy that the attachment of nitro group to the compound 4 leading to compounds $\mathbf{7 a - b}$ showed significant effect on the inhibitory activity of the ALR2 inhibition, and even compound $\mathbf{7 a}$ was more active than the carboxylic acid compound 6. However, nitro derivatives of 9a-b and 11a-b all showed low activity. Thus, nitro derivatives based on benzothiazine 1,1-dioxide have remained optimized.

Table 1. Biological data for the synthesized compounds

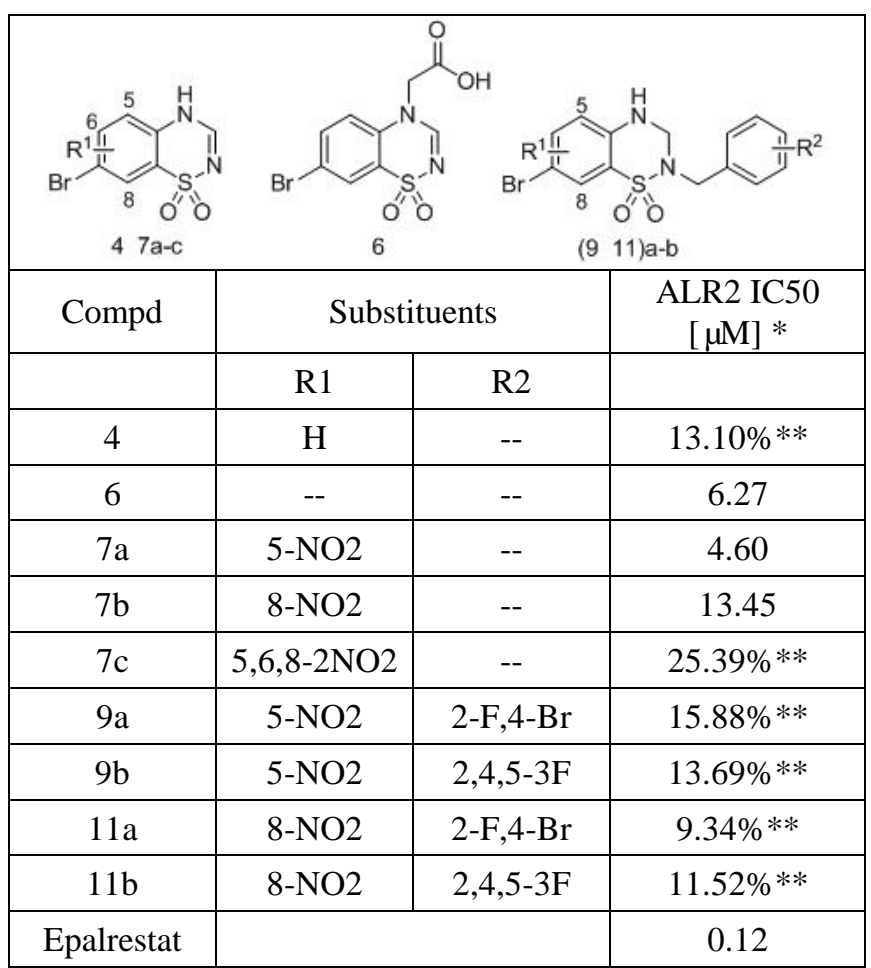

* $\mathrm{IC}_{50}$ values represent the concentration of the tested compounds required to decrease enzymatic activity by $50 \%$. ** Inhibitory effects were evaluated at a concentration of $10 \mu \mathrm{M}$.

\subsection{Molecular docking}

Molecular modeling was performed to get a better understanding of the ALR2 inhibitory potency of the newly synthesized compounds at a molecular level and to propose a binding mode, which used Molegro Virtual Docker, version 5.0 (CLC bio, Aarhus, Denmark). Compound $\mathbf{7 a}$, the most active as described above, was docked into the binding pocket of the human ALR2/NADP+/lidorestat complex (PDB entry code $1 \mathrm{Z3N}$ ) as shown in Figure 3. 

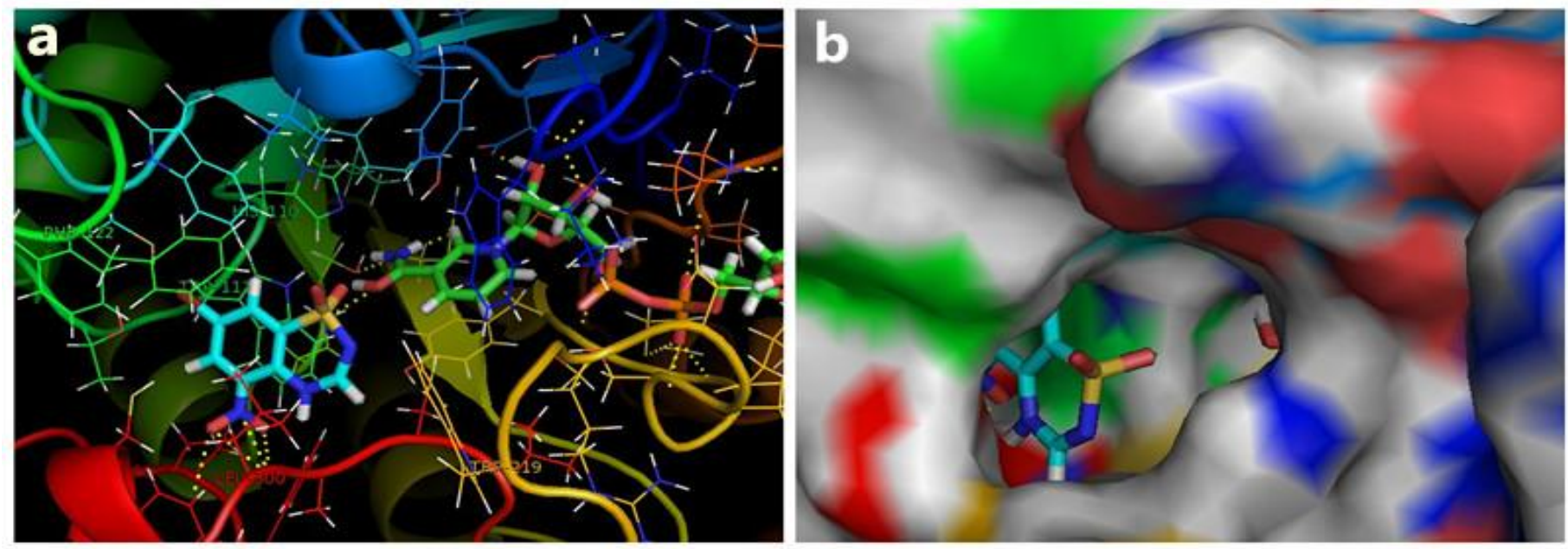

Figure 3. Compound 7a bound into the active site of ALR2. (a) Protein structure is shown as cartoon diagrams with the side chains of the key receptor residues in proximity of the docked ligands are labeled. Ligand 7a, and NADP are shown as stick models. Docked pose of 7a is shown in cyan $(\mathrm{C})$, red $(\mathrm{O})$, blue $(\mathrm{N})$, yellow $(\mathrm{S})$. Nonpolar hydrogens have been removed for clarity. Hydrogen bonds are represented by yellow lines. (b) Protein residues are in surface representation.

Docking results suggest that the inhibitor $7 \mathbf{a}$ is tightly bound in the active site of ALR2. As an electronic acceptor, nitryl at the C6 position of benzothiadiazine 1,1-dioxide also joint connection with the hydroxy group through tight hydrogen bonds. Therefore, further studies about nitro derivatives of benzothiadiazine 1,1-dioxide as aldose reductase inhibitors is necessary and meaningful.

\section{CONCLUSION}

New nitro-benzothiadiazine 1,1-dioxide derivatives were synthesized, and some of them showed significant inhibitory activity against ALR2 and potential for the development of effective noncarboxylic acid ARIs.

\section{REFERENCES}

[1] Michael Brownlee, M.D., Anthony Cerami, Ph.D. \& Helen Vlassara, M.D. 1988. Advanced glycosylation end products in tissue and the biochemical basis of diabetic complications. Journal of Medicine 318:1315-1321.

[2] P. Alexiou, K. Pegklidou, M. Chatzopoulou, I. Nicolaou, V.J. Demopoulos. 2009. Aldose reductase enzyme and its implications to major health problems of the 21 st century. Current Medicinal Chemistry 16: 734-752.

[3] a) Y. L. Kao, K. Donaghue, A. Chan, J. Knight, M. Silink. 1999. A novel polymorphism in the aldose reductase gene promoter region is strongly associated with diabetic retinopathy in adolescents with type 1 diabetes. Diabetes 48: 1338-1340; b) D. K. Moczulski, W. Burak, A. Doria, M. Zychma, E. Zukowska-Szczechowska, J. H. Warram, W. Grzeszczak. 1999. The role of aldose reductase gene in the susceptibility to diabetic nephropathy in Type II (noninsulin-dependent) diabetes mellitus. Diabetologia 42: 9497.

[4] C. La Motta, S. Sartini, S. Salemo, F. Simorini, S. Taliani, A. M. Marini, F. DaSettimo, L. Marinelli, V. Limongelli,
E. Novellino. 2008. Acetic acid aldose reductase inhibitors bearing a five-membered heterocyclic core with potent topical activity in a visual impairment rat model. Journal of Medicine Chemistry 51: 3182-3193.

[5] a) Kinoshita, J. H.; Nishimura, C. 1988. The involvement of aldose reductase in diabetic complications. Diabetes Metablism Reviews 4: 323; b) Yabe-Nishimura, C. Pharmacol. 1998. Aldose reductase in glucose toxicity: a potential target for the prevention of diabetic complications. Pharmacological Reviews 50: 21; c) Chung, S. S.; Chung, S. K. 2003. Genetic analysis of aldose reductase in diabetic complications. Current Medicinal Chemistry 10(15): 1375.

[6] a) S. Ao, Y. Shingu, C. Kikuchi, Y. Takano, K. Nomura, T. Fujiwara, Y. Ohkubo, Y. Notsu, I. Yamaguchi. 1991. Characterization of a novel aldose reductase inhibitor, FR74366, and its effects on diabetic cataract and neuropathy in the rat. Metabolism 40: 77-87; b) M. C.Van Zandt, M. L. Jones, D. E. Gunn, L. S. Geraci, J. H. Jones, D. R. Sawicki, J. Sredy, J. L. Jacot, A. T. DiCioccio, T. Petrova, A. Mitschler, A. D. Podjarny. 2005. Human aldose reductase in complex with NADP+ and the inhibitor lidorestat at 1.04 angstrom. Journal of Medicine Chemistry 48: 3141-3152; c) B. L. Mylari, E. R. Larson, T. A. Beyer, W. J. Zembrowski, C. E. Aldinger, M. F. Dee, T. W. Siegel, D. H. Singleton. 1991. Novel, potent aldose reductase inhibitors: 3,4-dihydro-4-oxo-3-[[5(trifluoromethyl)-2-benzothiazolyl] methyl]-1phthalazineacetic acid (zopolrestat) and congeners. Journal of Medicine Chemistry 34: 108-122; d) C. La Motta, S. Sartini, L.Mugnaini, F. Simorini, S. Taliani, S. Salerno, A. M. Marini, F. Da Settimo, A. Lavecchia, E. Novellino, M. Cantore, P. Failli, M. Ciuffi. 2007. Pyrido[1,2-a]pyrimidin4-one derivatives as a novel class of selective aldose reductase inhibitors exhibiting antioxidant activity. Journal of Medicine Chemistry 50: 4917-4927; e) F. Da Settimo, G. Primofiore, C. La Motta, S. Sartini, S. Taliani, F. Simorini, A. M. Marini, A. Lavecchia, E. Novellino, E. Boldrini. 2005. Naphtho[1,2- $d]$ isothiazole acetic acid derivatives as a novel class of selective aldose reductase inhibitors. Journal of Medicine Chemistry 48(22): 68976907; f) F. Da Settimo, G. Primofiore, A. Da Settimo, C. La Motta, F. Simorini, E. Novellino, G. Greco, A. 
Lavecchia, E. Boldrini. 2003. Novel, highly potent aldose reductase inhibitors: cyano(2-oxo-2,3-dihydroindol-3yl)acetic acid derivatives. Journal of Medicine Chemistry 46(8): 1419-1428; g) P. Alexiou, V. J. Demopoulos. 2010. A diverse series of substituted benzenesulfonamides as aldose reductase inhibitors with antioxidant activity: design, synthesis, and in vitro activity. Journal of Medicine Chemistry 53(21): 7756-7766. h) C. La Motta, S. Sartini, L. Mugnaini, F. Simorini, S. Taliani, S. Salerno, A. M. Marini, F. D. Settimo, A. Lavecchia, E. Novellino, M. Cantore, P. Failli, M. Ciuffi. 2007. Pyrido[1,2-a]pyrimidin4-one derivatives as a novel class of selective aldose reductase inhibitors exhibiting antioxidant activity. Journal of Medicine Chemistry 50(20): 4917-4927.

[7] a) X. Chen, C. J. Zhu, F. Guo, X. W. Qiu, Y. C. Yang, S. Z. Zhang, M. L. He, S. Parveen, C. J. Jing, Y. Li, B. Ma. 2010. Acetic acid derivatives of 3,4-dihydro-2H-1,2,4benzothiadiazine 1,1-dioxide as a novel Class of Potent aldose reductase inhibitors. Journal of Medicine Chemistry 53: 8330-8344; b) X. Chen, Y. C. Yang, B. Ma, S. Z.
Zhang, M. L. He, D. Q. Gui, S. Hussain, C. J. Jing, C. J. Zhu, Q. Yu, Y. Liu. 2011. Design and synthesis of potent and selective aldose reductase inhibitors based on pyridylthiadiazine scaffold. European Journal of Medicinal Chemistry 46: 1536-1544; c) X. Chen, S. Z. Zhang, Y. C. Yang, S. Hussain, M. L. He, D. Q. Gui, B. Ma, C. J. Jing, Z. X. Qiao, C. J. Zhu, Q. Yu. 2011. 1,2Benzothiazine 1,1-dioxide carboxylate derivatives as novel potent inhibitors of aldose reductase. Bioorganic \& Medicinal Chemistry 19: 7262-7269; d) S. Z. Zhang, X. Chen, S. Parveen, S. Hussain, Y. C. Yang, C. J. Jing, C. J. Zhu. 2013. Effect of C7 modifications on benzothiadiazine-1,1-dioxide derivatives on their inhibitory activity and selectivity toward aldose reductase. ChemMedChem 8: 603-613.

[8] Costantino. L, Rastelli. G, Vianello. P, Cignarella. G, Barlocco. D. 1999. Diabetes complications and their potential prevention: aldose reductase inhibition and other approaches. Medicine Research Reviews 19(1): 3-23. 